\title{
Knowledge, Attitude and Complications Related to Ear Candling: A Pilot Study among Medical Students
}

\author{
Eman Abduullah Hajr ${ }^{1,2 *}$ \\ ${ }^{1}$ Otolaryngology Department, Imam Mohammad Ibn Saud Islamic University (IMSIU), KSA \\ ${ }^{2}$ Otology Neurotology Fellowship, King Abdullah Ear Specialist Centre (KAESC) \\ Submission: July 07, 2021; Published: July 26, 2021
}

*Corresponding author: Eman A Hajr, Otology Neurotology Fellowship, King Abdullah Ear Specialist Centre (KAESC), Otolaryngology Department, Imam Mohammad Ibn Saud Islamic University (IMSIU), Riyadh, KSA

\section{Abstract}

Background: Impacted cerumen is one of the common complaints for seeking medical care for ear-related problems. Ear candling (EC) is an alternative method for dealing with impacted cerumen, where it can be self-administered or performed by an assistant.

Objectives: To determine the knowledge of EC among medical students and to examine students' attitudes toward its utilization.

Design: A cross-sectional questionnaire-based study.

Settings: College of Medicine, Al-Imam Muhammad Ibn Saud Islamic University (IMSIU).

Study Population and Methods: Medical students in IMSIU in the preclinical year were contacted through each group leader and asked for voluntary participation in filling up an online questionnaire about EC.

Main Outcome Measure: Prevalence of EC usage among participants and general knowledge and attitude towards its utilization.

Sample Size: We analyzed 81 responses from one medical school in Riyadh/KSA.

Results: Out of a total of six participants who used EC techniques, three reported getting the candle from a friend or relative, and the remaining three through online shopping. Ear discharge and pain were the most frequent adverse events observed during EC in five and four participants, respectively. Burning sensation and decreased hearing were reported as solitary events.

Conclusion: In general, participants seemed unaware and had insufficient knowledge of EC. Understanding the knowledge of and the attitude towards EC among a sample of medical students would open the door for further projects aimed at increasing the awareness of EC as a concept of self-treatment in the local community.

Limitations: The participants were enrolled from one medical college and low number of participations were achieved, a further study involving more participant and extended to involve different community members is indicated.

Keywords: Candling; Ear wax; Cerumen; Saudi Arabia

\section{Introduction}

Cerumen, commonly known as earwax, is a naturally occurring substance that can provide protection and lubrication to the external auditory canal and comprises of a mixture of desquamated epithelial layer and ceruminous and sebaceous gland secretions [1]. In normal situation, the ear had a selfcleaning mechanism to expel the cerumen and migrate it out of the canal this mechanism is assisted by normal jaw movement [2]. However, when this cleaning mechanism fails, or is disrupted for any reason, the cerumen accumulates and may be impacted inside the external canal. Impacted cerumen is a common complaint for seeking medical care for ear-related problems [3]. Being a common problem, it represents an increased interest for the community to use complementary alternative medicine for its treatment.

Ear candling/coning (EC) is an alternative method for dealing with impacted cerumen, where it can be self-administered or 
performed by an assistant. It involves placing a hollow tube into the ear while it is pointing upward and lighting the other end. The tube is made of beeswax, essential oils, and organic linen. A dark waxy substance is left in the canal after use is believed to be the debris and cerumen by the EC user [4]. Since there is no scientific basis for this treatment and its use may result in serious injuries, the Food and Drug Administration in the USA has issued a warning to consumers not using ear candles [5]. EC is widely available to order on the Internet; hence, it may be misused by the public for treating ear-related complaints, instead of seeking appropriate medical care.

In KSA, there are no local reports about the use of EC, and we believe that during the COVID-19 pandemic, many community members shifted toward complementary and alternative medicine (CAM) for different reasons. However, medical students represent an important sample in the local community; in fact, they are the bridge between specialized medical services and the general population for most voluntary activities and awareness camps. Understanding the perception of medical students toward different options in alternative medicine will guide specialized doctors in planning community awareness programs. Moreover, medical students can understand health-related advertising materials and online shopping (in English), as they frequently use English as their main language in education in medical colleges in Saudi Arabia. In a specialized ENT clinic, we started seeing patients with complaints related to the use of EC, especially after the quarantine period. Hence, we plan to uncover the knowledge and attitude toward EC and start with this pilot report on medical students.

\section{Materials and Methods}

This cross-sectional observational pilot study was conducted between January and March 2021 at the College of Medicine,
Al-Imam Muhammad Ibn Saud Islamic University (IMSIU). The study was approved by the Institutional Review Board of the College of Medicine project number: 93-2020. Data was collected using online questionnaires. Students in preclinical years were included. Each group was contacted through a group leader who was asked to distribute the questionnaire among the group members. Participation was voluntary and the questionnaires included four parts. The first part was an informed consent form that assured participants of the confidentiality of their responses; the participants' personal information was not collected. The second part addressed general knowledge about EC. The third part concentrated on the attitude of the participants and was scored on a five-point Likert scale: strongly disagree, disagree, not sure/neutral, agree, and strongly agree. The last (fourth) part was designed to cover the actual practice of EC among the study sample (previous use/indications/possible complications).

\section{Statistical Analysis}

All statistical analyses were performed using IBM SPSS version 19. Descriptive statistics were used to outline the characteristics of responders using frequencies and percentages for categorical variables and mean (standard deviation) or median (range) values for continuous variables. We used the chi-square test to determine the association of variables based on gender and age groups or clinical and pre-clinical years.

\section{Results}

\section{Baseline characters of included subjects}

We analyzed 81 responses from one medical school in Riyadh/ KSA. The median age of the participants was 21 years, ranging from 19 to 25 years. Women were predominant in the sample, accounting for $65(80.2 \%)$, while $16(19.8 \%)$ subjects were men (Figure 1).

Figure 1: Baseline characters of included subjects.

\section{Outcomes}

Regarding EC attitude (Table 1), most participants (34.6\%) agreed that EC treatment can treat ear problems, while 30
(37\%) were neutral or unsure about it. A large proportion of participants $30(, 37 \%)$ agreed that EC treatment was used inside the ear. However, $28.4 \%$ were unsure or disagreed $(23.5 \%)$. 


\section{Global Journal of Otolaryngology}

Approximately 30 participants (37\%) reported "Neutral" for the possibility of using EC treatment anytime, followed by 33 (40\%) and $11(13.6 \%)$ who disagreed or strongly disagreed with this concern, respectively. Regarding the use of EC practice as an alternative for ENT clinics to treat ear blockage or other ear complaints, most participants disagreed (30.9\%) or strongly disagreed (29.6\%). Additionally, the majority disagreed and strongly disagreed (74\%) about using EC treatment for everyone. Further, about $61.7 \%$ disagreed/strongly disagreed about selfperforming EC at home. Concerning the safety of EC treatment, more than one-third of participants (41.9\%) were negative about the safety of the procedure, represented as disagree and strongly disagree, while a similar proportion (42\%) had a neutral attitude towards it and only $16 \%$ endorsed the procedure.

Table 1: Medical students' knowledge about ear candling.

\begin{tabular}{|c|c|c|}
\hline Item & $\mathbf{N}$ & $\%$ \\
\hline \multicolumn{3}{|c|}{ 1. Ear candling treatment can treat ear problem } \\
\hline Agree & 28 & 34.6 \\
\hline Disagree & 11 & 13.6 \\
\hline Neutral & 30 & 37 \\
\hline Strongly agree & 3 & 3.7 \\
\hline Strongly disagree & 9 & 11.1 \\
\hline \multicolumn{3}{|c|}{ 2. Ear candling treatment is used inside the ear } \\
\hline Agree & 30 & 37 \\
\hline Disagree & 19 & 23.5 \\
\hline Neutral & 23 & 28.4 \\
\hline Strongly agree & 2 & 2.5 \\
\hline Strongly disagree & 7 & 8.6 \\
\hline \multicolumn{3}{|c|}{ 3. Ear candling treatment can be used anytime } \\
\hline Agree & 6 & 7.4 \\
\hline Disagree & 33 & 40.7 \\
\hline Neutral & 30 & 37 \\
\hline Strongly agree & 1 & 1.2 \\
\hline Strongly disagree & 11 & 13.6 \\
\hline \multicolumn{3}{|c|}{ Ear candling practice can be used as an alternative for ENT clinic to treat ear blockage or other ear complaints } \\
\hline Agree & 16 & 19.8 \\
\hline Disagree & 25 & 30.9 \\
\hline Neutral & 13 & 16 \\
\hline Strongly agree & 3 & 3.7 \\
\hline Strongly disagree & 24 & 29.6 \\
\hline \multicolumn{3}{|c|}{ 5. Ear candling treatment can be used for everyone } \\
\hline Agree & 2 & 2.5 \\
\hline Disagree & 39 & 48.1 \\
\hline Neutral & 18 & 22.2 \\
\hline Strongly agree & 1 & 1.2 \\
\hline Strongly disagree & 21 & 25.9 \\
\hline \multicolumn{3}{|c|}{ 6. Ear candling treatment can be done ourselves at home } \\
\hline Agree & 11 & 13.6 \\
\hline Disagree & 29 & 35.8 \\
\hline Neutral & 19 & 23.5 \\
\hline
\end{tabular}




\section{Global Journal of Otolaryngology}

\begin{tabular}{|c|c|c|}
\hline Strongly agree & 1 & 1.2 \\
\hline Strongly disagree & 21 & 25.9 \\
\hline \multicolumn{3}{|c|}{ 7. Ear candling is safe treatment } \\
\hline Agree & 12 & 14.8 \\
\hline Disagree & 21 & 25.9 \\
\hline Neutral & 34 & 42 \\
\hline Strongly agree & 1 & 1.2 \\
\hline Strongly disagree & 13 & 16 \\
\hline
\end{tabular}

Table 2: Medical students' attitude and complications related to ear candling.

\begin{tabular}{|c|c|c|}
\hline Item & $\mathbf{N}$ & $\%$ \\
\hline \multicolumn{3}{|c|}{ Have you ever used the ear candling techniques } \\
\hline No & 75 & 92.6 \\
\hline Yes & 6 & 7.4 \\
\hline \multicolumn{3}{|c|}{ Practice section } \\
\hline From friend or relative & 3 & 3.7 \\
\hline I did not use it & 75 & 92.6 \\
\hline Through internet shopping & 3 & 3.7 \\
\hline \multicolumn{3}{|c|}{ How much it cost as SAR } \\
\hline 30-Oct & 1 & 1.2 \\
\hline 20 & 1 & 1.2 \\
\hline 30 & 1 & 1.2 \\
\hline 100 & 1 & 1.2 \\
\hline Do not know & 77 & 95 \\
\hline \multicolumn{3}{|c|}{ What was the reason for using the ear candling } \\
\hline No answer & 16 & 19.8 \\
\hline I did not use it; & 56 & 69.1 \\
\hline To treat ear blockage; & 3 & 3.7 \\
\hline To treat ear blockage; I did not use it; & 2 & 2.5 \\
\hline To treat ear blockage; To treat ear pain; & 1 & 1.2 \\
\hline $\begin{array}{l}\text { To treat ear blockage; To treat ear pain; To treat ear inching; To } \\
\text { treat ringing sound in the ear; Sinusitis; }\end{array}$ & 1 & 1.2 \\
\hline To treat ear inching; & 1 & 1.2 \\
\hline To treat ear pain; & 1 & 1.2 \\
\hline \multicolumn{3}{|c|}{ What was the after-use conditions } \\
\hline No answer & 17 & 21 \\
\hline Better & 3 & 3.7 \\
\hline I did not use it & 58 & 71.6 \\
\hline Worse & 3 & 3.7 \\
\hline \multicolumn{3}{|c|}{ During or after use did you noticed any of the flowing } \\
\hline No answer & 56 & 69.1 \\
\hline Pain & 4 & 4.9 \\
\hline
\end{tabular}




\section{Global Journal of Otolaryngology}

\begin{tabular}{|c|c|c|}
\hline Burning sensation & 1 & 1.2 \\
\hline Decree's hearing & 1 & 1.2 \\
\hline Didn't use & 13 & 16 \\
\hline Ear discharge & 5 & 6.2 \\
\hline No thing & 1 & 1.2 \\
\hline \multicolumn{3}{|c|}{ Frequency of use } \\
\hline No answer & 27 & 33.3 \\
\hline Both ears once & 1 & 1.2 \\
\hline I did not use it & 49 & 60.5 \\
\hline More than one time & 1 & 1.2 \\
\hline One ear once & 3 & 3.7 \\
\hline \multicolumn{3}{|c|}{ Did you visit a doctor after use } \\
\hline No answer & 27 & 33.3 \\
\hline I did not use it & 49 & 60.5 \\
\hline No & 2 & 2.5 \\
\hline Yes & 3 & 3.7 \\
\hline \multicolumn{3}{|c|}{ What was the reason for not using ear candling before } \\
\hline No answer & 8 & 9.9 \\
\hline I hear a warning about it & 3 & 3.7 \\
\hline All the above & 1 & 1.2 \\
\hline Did not hear about it before & 21 & 25.9 \\
\hline I Did not use it & 1 & 1.2 \\
\hline I do not have any reason to use ear treatment & 24 & 29.6 \\
\hline I do not think it is beneficial & 9 & 11.1 \\
\hline It not safe for use & 11 & 13.6 \\
\hline Not available in the local market & 3 & 3.7 \\
\hline
\end{tabular}

A significant proportion of our participants did not use EC techniques $(92.6 \%)$, because they did not have any reason to use ear treatment $(29.6 \%)$ or did not hear about them previously (25.9\%). Out of a total of six participants who used EC techniques, three reported getting the candle from a friend or relative, and the remaining three through online shopping. Ear discharge and pain were the most frequent adverse events observed during EC in five and four participants, respectively. Burning sensation and decreased hearing were reported as solitary events. Three participants reported a better condition after using EC, while another three reported a worsening condition. Concerning the frequencies of use, three participants gave an account of using EC once for one ear and one participant once for both ears, while only one participant used EC more than one time. On the other hand, three participants declared that they visited a doctor after EC.

\section{Discussion}

In this study, we explored the knowledge and altitude of a pilot sample of medical students towards EC. To our knowledge, this is the first study on EC in Saudi Arabia, in general, and for medical students in. Several studies have addressed the perception and attitude of medical students toward different types of alternative medicine but did not include the use of EC. Medical students' knowledge of CAM modalities in general differs from country to country. In 2018, Albader et al. published a paper on the attitude of Saudi medical students toward alternative medicine. They included candidates from King Saud University (KSU) and Majmaah University (MU). Among 17 modalities of alternative medicine included in that report, bloodletting was the most known modality to the students, and around one-third reported self-use of CAM modalities [6]. In another local study, spiritual 
healing and magnetic therapy were the most used modalities [7]. Although the EC was not included in that previous study, it was interesting to explore the knowledge of medical students in the field of alternative medicine.

On the other hand, medical students can be considered as references for medical information and asked to provide medical opinions on health-related issues among their families, close relatives, and friends. Therefore, in this research, we are interested in exploring the practice of EC as an alternative treatment by medical students as a first step in exploring wider community members as the next step. The majority of participants agreed $(34.6 \%)$ or were neutral $(37 \%)$ to the statement, 'ear candling treatment can treat ear problems,' and there is no scientific basis to support that concept. Since 1996, Seely et al. investigated the efficacy of EC in vitro and in vivo by analyzing the procedure with tympanogram, which did not show any changes to negative pressure. Additionally, EC was attempted in a group of volunteers in a clinical study and was found inefficient [8]. In 2004, Ernst reviewed the literature on EC and reported that this method did not provide any supporting evidence and was unscientific [9].

Although most of the candidates (34.6\%) agreed that EC can treat ear problems, only $7.4 \%$ knew how to use EC properly because it does not have widespread usage in the local community as compared to other Asian cultures [10,11]. It was reassuring to know that the majority of our participants did not use EC techniques (92.6\%), but when we asked about the main cause, only $11(13.6 \%)$ respondents questioned its safety, while a higher number of respondents did not have any reason to use ear treatment $(29.6 \%)$ or had not heard about it previously (25.9\%), indicating that the non-use status was related to a lack of knowledge rather than actual awareness of the harm caused by EC.

Of the six participants who used EC techniques, ear discharge and pain were the most frequent adverse events noticed during EC in five and four participants, respectively. Burning sensation and reduced hearing were reported as solitary events. These adverse events were consistent with reported clinical cases about the negative effect of EC from around the world, for example, complete or partial occlusion of the ear canal with candle, 4 burn,8 and tympanic membrane perforation [12]. Three of the participants reported getting the candle from a friend or relative, and another three through online shopping. In Saudi Arabia, we do not have a local report about the actual use of self-treatment and EC during the pandemic COVID-19, but we start seeing cases with complications related to EC, especially after the lockdown. This could represent the tip of the iceberg and it may be worth exploring the concept of EC and other modalities of self-treatment in our local community in comparison to other communities $[13,14]$.

\section{Conclusion}

Understanding the knowledge and attitude of EC among a sample of medical students would open the door for further projects about the awareness of EC as a concept of self-treatment in the local community. This concept could be improved by educating the public about the harmful effects of irrational use of EC.

\section{Acknowledgment}

The author extends their appreciation to the Deanship of Scientific Research at Imam Mohammad Ibn Saud Islamic University for funding this work through Research Group no. RG21-11-03.

\section{References}

1. Guest JF, Greener MJ, Robinson AC, Smith AF (2004) Impacted cerumen: composition, production, epidemiology, and management. $Q$ J Med 97(8): 477-488.

2. Alberti PW (1964) Epithelial migration on the tympanic membrane. J Laryngol Otol 78: 808-830.

3. Sharp JF, Wilson JA, Ross L, Barr Hamilton RM (1990) Earwax removal: a survey of current practice. BMJ 301(6763): 1251-1253.

4. Zackaria M, Aymat A (2009) Ear candling: a case report. Eur J Gen Pract 15(3): 168-169.

5. Food and Drug Administration. Advice for patients: ear candles. [Cited Aug 26, 2015].

6. Albadr BO, Alrukban M, Almajed J, Alotaibi K, Alangari A, et al. (2018) Attitude of Saudi medical students towards complementary and alternative medicine. J Family Community Med 25(2): 120-126.

7. Alzahrani SH, Bashawri J, Salawati EM, Bakarman MA (2016) Knowledge and attitudes towards complementary and alternative medicine among senior medical students in King AbdulAziz University, Saudi Arabia. Evid Based Complement Alternat Med 2016: 9370721.

8. Seely DR, Quigley SM, Langman AW (1996) Ear candles - efficacy and safety. Laryngoscope 106(10): 1226-1229.

9. Ernst E (2004) Ear candles: a triumph of ignorance over science. J Laryngol Otol 118(1): 1-2.

10. Hamdan NKA, Lean QY, Neoh CF, Abdullah AH, Lim SM, et al. (2020) Knowledge and perception of facial candling for allergic rhinitis among university staff and students. Evid Based Complement Alternat Med 5713134 .

11. Ismail NFF, Neoh CF, Lean QY, Abdullah AH, Lim SM, Ramasamy K et al. (2018) Facial candling for the treatment of allergic rhinitis in young adults: A qualitative study. J Pharm Bioallied Sci 10(4): 199-207.

12. Rafferty J, Tsikoudas A, Davis BC (2007) Ear candling: should general practitioners recommend it? Can Fam Physician 53(12): 2121-2122.

13. Makowska M, Boguszewki R, Nowakowski M, Podkowińska M (2020) Self-medication-related behaviors and Poland's COVID-19 lockdown. Int J Environ Res Public Health 17(22): 8344.

14. Onchonga D, Omwoyo J, Nyamamba D (2020) Assessing the prevalence of self-medication among healthcare workers before and during the 2019 SARS-CoV-2 (COVID-19) pandemic in Kenya. Saudi Pharm J 28(10): 1149-1154. 
(C) Commons Attribution 4.0 License

(CC) DY 10.19080/GJO.2021.24.556142

\section{Your next submission with Juniper Publishers will reach you the below assets}

- Quality Editorial service

- Swift Peer Review

- Reprints availability

- E-prints Service

- Manuscript Podcast for convenient understanding

- Global attainment for your research

- Manuscript accessibility in different formats ( Pdf, E-pub, Full Text, Audio)

- Unceasing customer service

Track the below URL for one-step submission https://juniperpublishers.com/online-submission.php 